Research Article

\title{
Presentation of Analytical Methods for Better Decision Making about the Most Important Factor Influencing Rural Accidents
}

\author{
Seyed Mohsen Hosseinian (D), ${ }^{1}$ Vahid Najafi Moghaddam Gilani $(D)$, \\ Hossein Tahmasbi Amoli, ${ }^{2}$ Mohammad Nikookar, ${ }^{3}$ and Alireza Orouei ${ }^{4}$ \\ ${ }^{1}$ School of Civil Engineering, Iran University of Science and Technology (IUST), Tehran, Iran \\ ${ }^{2}$ School of Engineering and Technology, Shomal University, Amol, Iran \\ ${ }^{3}$ School of Civil Engineering, University of Guilan, Rasht, Iran \\ ${ }^{4}$ School of Civil Engineering, Islamic Azad University, Semnan, Iran \\ Correspondence should be addressed to Vahid Najafi Moghaddam Gilani; vahid.moghaddam90@gmail.com
}

Received 29 January 2021; Revised 28 February 2021; Accepted 11 March 2021; Published 20 March 2021

Academic Editor: Mohammad Yazdi

Copyright (C) 2021 Seyed Mohsen Hosseinian et al. This is an open access article distributed under the Creative Commons Attribution License, which permits unrestricted use, distribution, and reproduction in any medium, provided the original work is properly cited.

\begin{abstract}
Due to population growth and the increasing number of vehicles on rural roads, traffic accidents have become one of the most important problems in the transportation system, which greatly affects the social and economic situation of the people. The main purpose of this study was to apply the analytical method to investigate the factors affecting the severity of traffic accidents on rural roads of Guilan, Iran, in order to determine the most effective factor in the occurrence of these accidents. At first, the frequency analysis was used to evaluate the variables and their frequency, then the Friedman test (FT) was applied to prioritize the factors, and the exploratory factor analysis (EFA) was used to determine the most effective factor in the occurrence of vehicle accidents in Guilan rural roads. Based on the FT, weather condition was the most important factor effective in these accidents. According to the results of the EFA, five factors were identified as the main factors involved in accidents in which the first factor contributing to accidents was the environmental factor, including weather condition and road surface condition. This indicates that concurrent result of the FT and the EFA, weather condition as an environmental factor, was identified as the most important factor affecting vehicle accidents on rural roads of Guilan. Finally, safety strategies were proposed to increase safety and reduce accidents along these roads.
\end{abstract}

\section{Introduction}

Traffic accidents are now a worldwide problem that annually kills a large number of people and brings huge economic costs to society $[1,2]$. Although the scientific growth and the advancement of technology in vehicles have created relative prosperity for humans, it has caused an important problem called road accidents [3] that has become one of the world's leading economic, social, and health hazards today and as one of the most important causes of mortality, disability, and damages in the world which is worryingly increasing $[4,5]$. World statistics show that the economic and human casualties of road accidents are high. Approximately 3700 people die every day and 1.35 million a year from traffic accidents, and nearly 50 million are injured or disabled every year. Road accidents are the eighth leading cause of death in the world $[6,7]$.

Factor analysis is a kind of approach that we may see in deep view in machine learning models [8-13] and various hybrid, enhanced, and boosted optimization techniques [14-27], and intelligent model studies [28-32] as well. For example, there are many well-established enhanced optimizers that have a style of factor analysis and evaluationbased decisions such as particle swarm optimizer (PSO) [33], 
Harris hawks optimizer (HHO) [34], whale optimizer algorithm (WOA) [35], differential search (DS) [36], ant colony optimizer (ACO) [37, 38], grey wolf optimizer (GWO) [25, 39], teaching-learning-based optimizer (TLBO) [40], differential evolution (DE) [41, 42], and other hybrid and enhanced methods [18, 20, 22, 26, 27]. Such techniques may also be applied to optimal control [43], analysis of machine learning models [44], optimal resource allocation [45], analysis of shuttlecock production [46], intelligent damage detection [47-49], image and video processing [50-55], and analysis of energy consumption [56]. They can also be applied to deep learning systems [57-61], adaptive control systems [62-65], and monitoring systems [66-69].

The safety of urban and rural roads depends on the behavior of road users, which is the result of each individual's beliefs and attitudes. So, knowing these can give a good understanding of traffic behaviors [70, 71]. In recent years, due to the unsuitable situation of traffic accidents in Iran, many steps have been taken to ensure traffic safety and improve transportation performance $[72,73]$. Since driving accidents are a multifactorial cause, identifying the causes and carefully examining the current situation is an essential step in reducing and controlling accidents that without it, the need to plan and manage them cannot be resolved. Therefore, the primary priority of the organizations concerned should be the identification of the root causes of accidents [73-76].

On rural roads of Iran, casualties due to accidental injury are almost 4.33 per 1000 and deaths from unintentional injuries are 5213 [77]. These findings illustrate the need for research and investment in rural infrastructure to improve the safety of rural roads [78]. Rural residents have more traveling compared with urban residents [79]. Although rural accidents may seem minor based on road casualties than urban roads, studying rural roads should be a priority with a social equity approach in mind [80].

In recent years, various studies have been carried out on the subject area of traffic safety on rural roads. Ghaffar et al. [81] attempted to assess the burden of road traffic injuries (RTIs) in Pakistan. Results showed that most accidents occurred from 12 to 18 . The incidence of RTI was the highest at the age of 16 to 45 and RTI in males was about three times greater than females. Labinjo et al. [82] conducted a population-based research to examine the RTI epidemiology in Nigeria. Results indicated that motorcycle accidents accounted for $54.33 \%$ of RTI. Increased risk of injury was associated with males among the age of 18 to 44 . Hu and Xiang [83] investigated the properties of rural road accidents by quantitative analysis. Results showed that $92.68 \%$ and $5.42 \%$ of fatalities happened in straight and curved roads, respectively. Moreover, fatalities in the daytime were more serious than those in the night time and driving a motor vehicle was the significant reason of fatalities. Zangooei Dovom et al. [84] examined the distribution of fatal accidents in Iran. According to the result, the males had more casualties compared with the females and most accidents had a peak at 21 to 30 ages for both genders. Moreover, the male-to-female ratio was 3.41 . They also indicated that the riskiest group was the male motorcyclist among all road users. López et al. [85] investigated the accident patterns and contributory factors on rural two-lane highways. Results of the study showed that the highest accident rate occurred in the condition of good weather, daylight, regular working day, the age group of 28-60, summer season, male gender, and from 12 to 18 . Zimmerman et al. [86] aimed to survey all people living in households within $200 \mathrm{~m}$ of two low volume rural roads in Tanzania. Results showed that the majority of crashes contained motorcycles (71\%) and the majority of victims were males (82\%) with 27 mean age. Lee and Jeong [87] investigated the properties of road collisions between rural roads and expressways in truck drivers. Results indicated that the crash rates were greater in the middle of the week. On rural roads, the accident rates in the daytime were greater $(81.7 \%)$ than those in the night time. Accidents mostly occurred in clear/cloudy weather (76.2\%). Most accidents happened on the straight roads $(62.2 \%)$, followed by intersections (15.4\%) and curved roads (9.4\%). CasadoSanz et al. [80] considered various factors in rural road accidents. The results showed that driver's age 30-45 years old, male driver, the middle of the week, good weather condition, and daylight had the maximum percentage of accidents on rural roads in Spain. Kamboozia et al. investigated various factors affecting the severity of accidents on rural roads of Iran and indicated that male drivers had a significant contribution in the occurrence of vehicle accidents. Moreover, 12 to $6 \mathrm{pm}$ had the highest accident rate (day time). They also revealed that the middle of the week recorded the greatest accident occurrence [88]. Recently, optimization algorithms are applicable for various engineering problems $[20-26,34,89,90]$.

Studies have shown the essential need to figure out the factors affecting accidents. The abundance of tourist and natural attractions, as well as the location of people living in the villages, has caused many traveling in the Guilan province. On the other hand, the distribution of urban and rural population centers has increased the traffic volume and, consequently, the number of traffic accidents in Guilan. So, this research aimed to explore the main features of road accidents and estimate that which of these factors become significant in affecting the probability of accident severity on rural roads of Guilan province to improve road safety and take the necessary safety measures.

\section{Methodology}

2.1. Data. The analytical methods used in this study included descriptive statistical surveys, Kolmogorov-Smirnov test (K-S), Friedman test (FT), and factor analysis (FA), and data used were 2481 road accidents resulting in fatal, injury, and damage accidents recorded from Guilan traffic police on rural roads from March 2014 to March 2019. Data included accident severity, accident time, accident day, accident season, road surface condition, geometry of accident location, daylight condition, type of vehicle accident, driver age, driver gender, weather condition, and reason of accident. The dependent variable in this study was different levels of accident severity, which initially were classified into three categories of injury and fatal and damage. Since the number 
of fatal accidents was smaller than the total number of accidents, fatal accidents were combined with injury accidents and the dependent variable was classified into two categories of injury/fatal and damage accidents. Figure 1 indicates the process of this research.

\subsection{Analytical Method}

2.2.1. Kolmogorov-Smirnov Test. The K-S test is commonly applied to investigate the normality of data [91] and is a nonparametric experiment for the data distribution [92]. By comparing the approximate significance test with $\alpha$, one can decide about the normality of data distribution. Considering $\alpha=0 / 05$ (with $95 \%$ certainty), if $p$ value $>0 / 05$, the null hypothesis of normality rejects. It means that data distribution is not normal [93]. The null hypothesis $\left(H_{0}\right)$ is that the data have a normal distribution, and the alternative hypothesis $\left(H_{a}\right)$ is that they have not [94]. Indeed this test is a compliance test distribution for quantitative data [95].

2.2.2. Friedman Test. The Friedman rank sum is normally utilized to compare the classifiers over multiple datasets. It is an extensively utilized nonparametric technique to analyze various associated specimens in computational biology and other areas. For instance, it is used for comparing the performance consequences of a group of (expression-oriented) classifiers over multiple datasets that cover benchmark functions, case problems, or performance indicators. The Friedman examination process is to analyze variance by ranks, indeed, detected rank scores or rank scores found by making numerical or ordinal results in order. It is utilized in case one which is not enthusiastic for making robust distributional assumptions. Simultaneous examinations are also proposed in addition to the ordinary normal approximation that uses the covariance outline of the distribution of the values of the variances in rank sums $[88,96,97]$.

2.2.3. Factor Analysis. The FA is one of the statistical methods for modeling the covariation among a dataset. It is used to determine the most influential variables when the number of variables is high and the relationships between them are unknown. The main purpose of using the FA is to reduce the dimensionality of a set of observed variables and determine the most important variables affecting the formation of phenomena. The FA is generally divided into two categories of the exploratory factor analysis (EFA) and the confirmatory factor analysis (CFA). The EFA is applied to identify the latent constructs when the structure of the relationships among variables is unknown and to generate hypotheses about their possible structures, while the CFA is used to identify variables by dimensions [98]. The EFA method was used in this research.

Since the sample size is a determining factor in the accuracy of element clustering by the FA technique, it must be assured that it is sufficient. In EFA, Kaiser-Mayer-Olkin (KMO) and Bartlett's test of sphericity are used to check the suitability of the data (sample size). The amount of KMO is between zero and one, and its small values (less than 0.5) indicate that the available correlations are not suitable for FA. The closer this value to one, the appropriate the data for the FA [99]. The output of Bartlett's test of sphericity can also be used to calculate chi-square amounts.

\section{Results and Discussion}

At first, using the K-S test, the parametric or nonparametric data were determined for the correct selection of statistical tests. Then, the FT was used to determine the priority of the factors, and the FA was applied to identify the underlying variables. Finally, by comparing different methods of analysis, the most important factors in increasing the likelihood of accidents were proposed to increase safety and reduce vehicle accidents on rural roads of Guilan.

\subsection{Frequency Analysis}

3.1.1. Investigating Accident Year. Analysis of accident statistics based on the years, as shown in Figure 2(a), showed that the highest number of accidents occurred in 2015-2016 $(n=562)$ and the least occurred in 2018-2019 $(n=428)$. Between 2014 and 2019, a total of 2481 vehicle accidents on rural roads were recorded; $84.92 \%$ of drivers were injured and dead, and $15.08 \%$ of vehicles were damaged, which is shown in Figure 2(b), indicating that rural vehicle accidents of Guilan often resulted in injuries/fatalities and there were few accidents resulted in damages. The highest percentage of injury/fatal and damage accidents occurred in 2017-2018 (19.99\%) and 2014-2015 (4.19\%), respectively. Figure 2(c) shows that the highest rates of male and female accidents occurred in 2015-2016 (21.28\%) and 2017-2018 (1.81\%), respectively, and the lowest accident rates for them occurred in 2018-2019 and 2014-2015 in the amount of $16.65 \%$ and $0.36 \%$, respectively. On the other hand, male drivers generally were accounted for the highest percentage of vehicle accidents (about 95.32\%). Male-to-female ratios indicated considerably higher male rates, maximum 50.88 times higher in 2014-2015, and on average 28.22.

3.1.2. Effect of Accident Time. Figure 3(a) shows that the highest percentage of vehicle accidents for both males and females $(44.06 \%)$ occurred from $12 \mathrm{pm}$ to $6 \mathrm{pm}$, of which $41.72 \%$ of these were males and only $2.34 \%$ were females. The lowest percentage of male and female drivers was $4.76 \%$ and $0.16 \%$ from 12 am to $6 \mathrm{am}$, respectively. Also, according to Figure 3(b), $37.36 \%$ of accidents as the highest percentage resulted in injuries and fatalities and only $6.69 \%$ resulted in damages between $12 \mathrm{pm}$ and $6 \mathrm{pm}$. The lowest injury/fatal (3.67\%) and damage (1.25\%) accidents were recorded from 12 am to $6 \mathrm{am}$.

3.1.3. Effect of Accident Day. According to Figure 4(a), $40.67 \%$ of vehicle accidents (as the highest percentage) happened in the middle of the week, of which $38.90 \%$ were males and $1.77 \%$ were females. From these days, $34.46 \%$ of drivers were injured and dead and $6.21 \%$ resulted in vehicle 


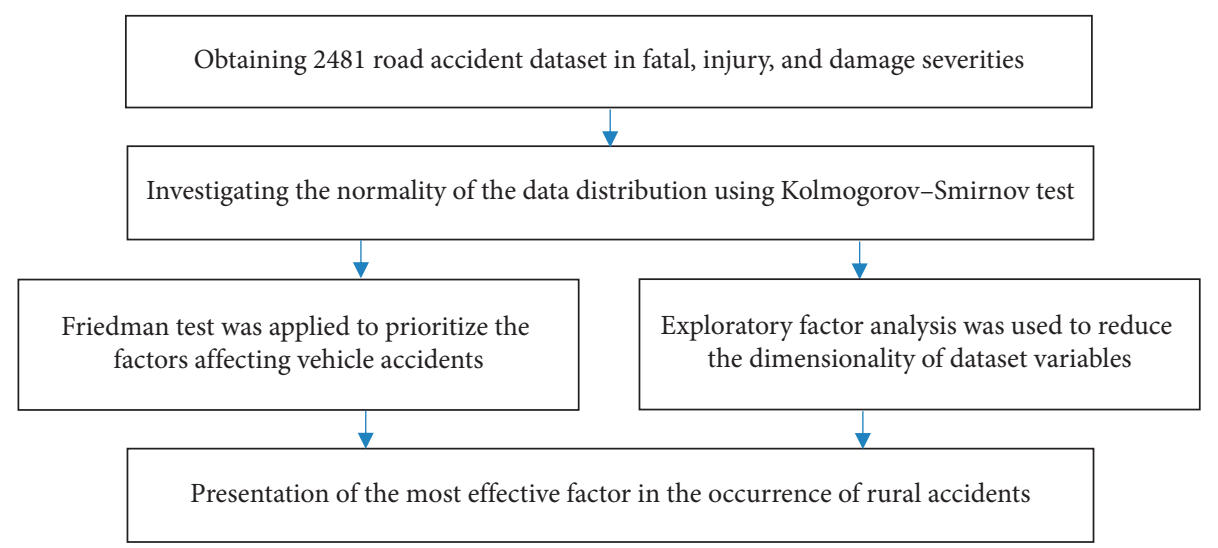

FIGURE 1: The steps of the research method.

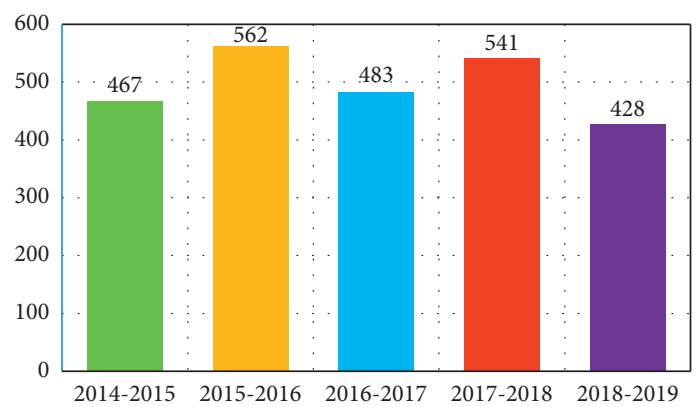

(a)

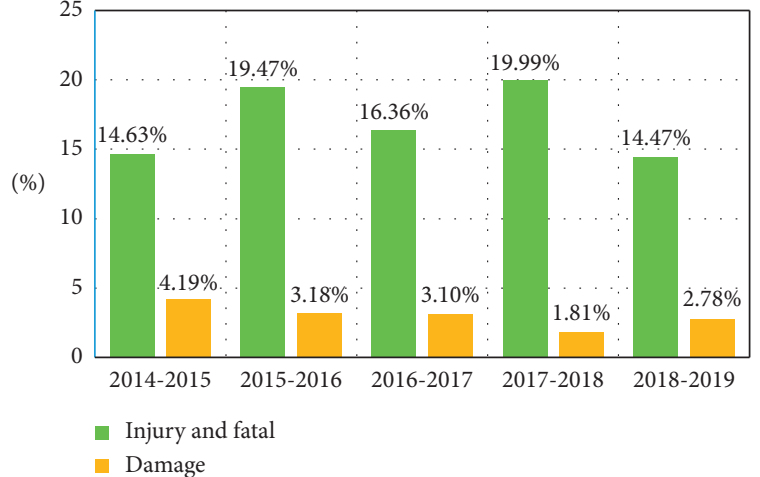

(b)

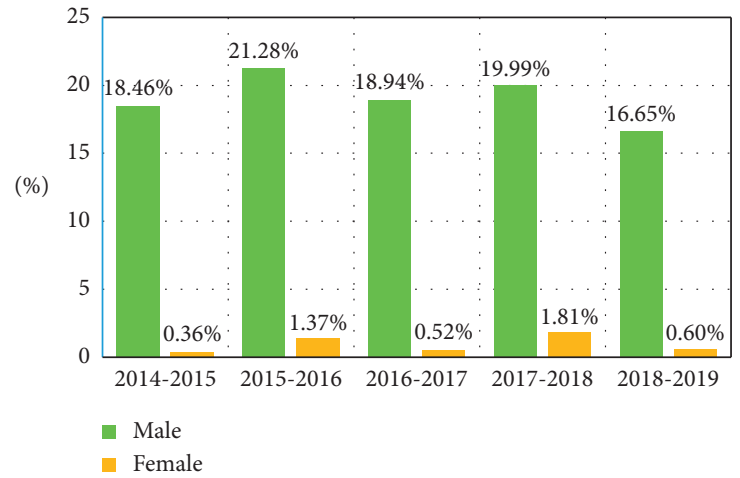

(c)

FIgURe 2: Accident statistics based on (a) accidents year; (b) accident severity and years; (c) driver gender and accidents year.

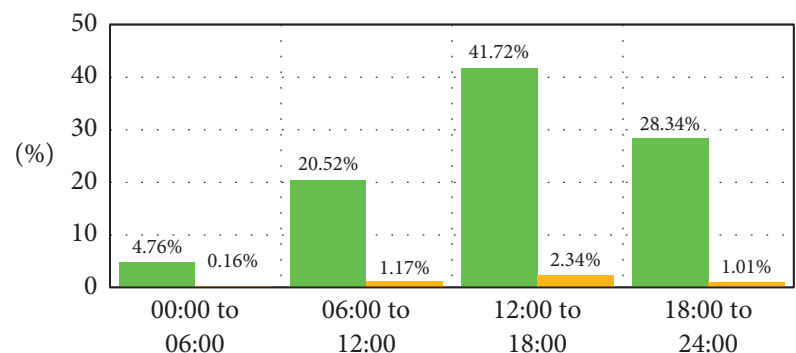

- Male

- Female

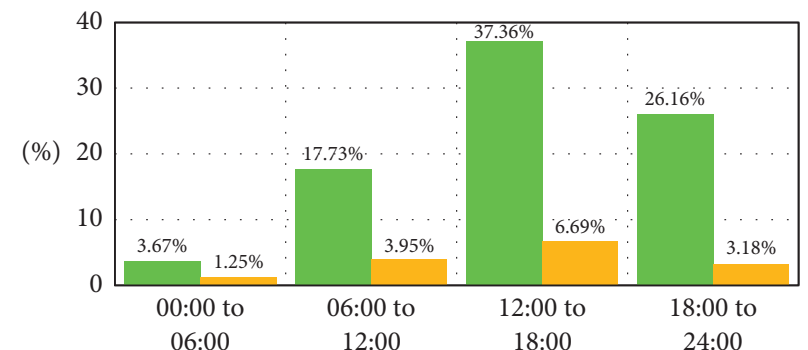

- Injury and fatal

- Damage

FIgURE 3: Accident statistics based on accident time and (a) driver gender; (b) accident severity. 


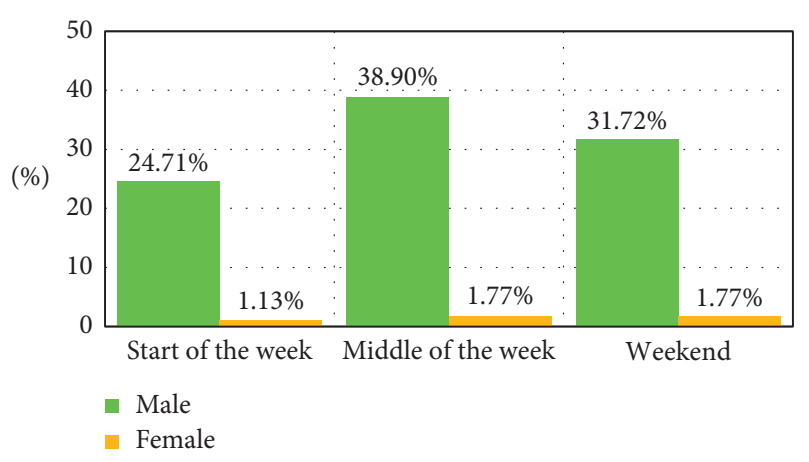

(a)

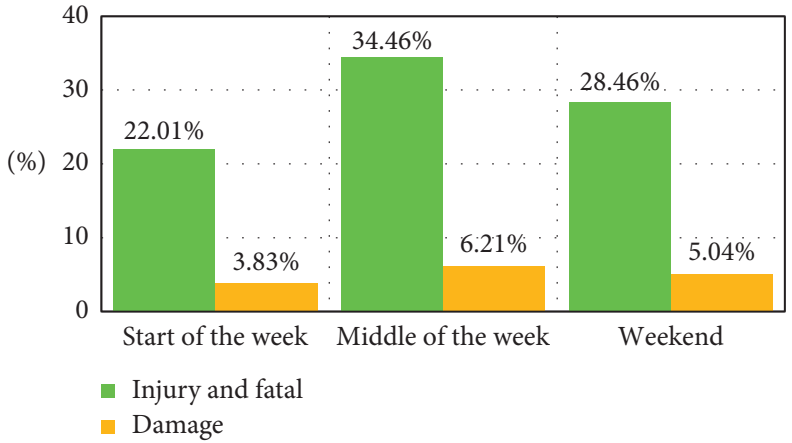

(b)

Figure 4: Accident statistics based on accident day and (a) driver gender; (b) accident severity.

damages by accidents, as shown in Figure 4(b). After that, most of the accidents were on weekends (33.49\%), of which $31.72 \%$ were males and the rest were females. The lowest percentage of accidents occurred during the start of the week, with male drivers accounting for $24.71 \%$ of accidents and female drivers accounting for $1.13 \%$ of them. On the other hand, as shown in Figure 4(b), the first few days of the week had the lowest percentage of injuries/fatalities (22.01\%) and damages $(3.83 \%)$.

3.1.4. Effect of Accident Season. As shown in Figure 5(a), $30.17 \%$ of accidents occurred in the summer season as the highest percentage, of which $28.71 \%$ were males and $1.46 \%$ were females and the minimum accidents happened in autumn. Female drivers had the lowest percentage of accidents in the autumn, with a magnitude of $0.77 \%$. According to Figure 5(b), the most serious and the lowest percentage of injury/fatal accidents occurred in summer $(27.63 \%)$ and winter $(15.91 \%)$, respectively, but it was the reverse for damage accidents $(4.80 \%$ for winter and $2.54 \%$ for summer).

3.1.5. Effect of Road Surface Condition. Three road surface conditions of dry, wet, and snowy were considered in the research. According to Figure 6(a), male drivers had the highest portion of accidents, accounting for $83.19 \%$, which occurred on the dry surface, $11.89 \%$ happened on wet surface, and the rest of male accidents $(0.24 \%)$ happened on snowy surface condition. Female drivers had the least participation in traffic accidents. It should be noted that there were no female driver accidents on the snowy surface. Results of Figure 6(b) show that dry surface condition caused the highest percentage of injuries/fatalities (75.01\%) and the lowest vehicle damage rate occurred in snowy pavement $(0.12 \%)$.

3.1.6. Effect of Geometry of Accident Location. The straight road, as shown in Figure $7(a)$, caused the most accidents $(74.57 \%)$, with the male and female drivers contributing $71.02 \%$ and $3.55 \%$, respectively. The intersection also caused the least percentage of accidents, with male drivers contributing $0.48 \%$ and females accounting for $0.04 \%$. According to Figure $7(\mathrm{~b})$, the straight road accounted for the largest percentage of all injury/fatal accidents, $62.31 \%$ of rural road accidents, followed by accidents on the horizontal curve $(22.25 \%)$, and the intersection (0.36). Also, the most damage accidents $(12.25 \%)$ occurred on the straight road, with a small percentage of them $(2.66 \%)$ on the horizontal curves and $0.16 \%$ on the intersection.

3.1.7. Effect of Daylight Condition. As shown in Figure 8(a), daylight condition was considered day, night, and sunrise/ sunset in this study. $71.06 \%$ of accidents occurred on day, of which $67.39 \%$ were males and $3.67 \%$ were females, followed by $27.81 \%$ of night accidents. The lowest percentage of accidents was at sunrise/sunset time (1.13\%). It should be noted that no female accidents occurred in sunrise/sunset. Results in Figure 8(b) show that among the accidents that occurred in the day, $59.77 \%$ resulted in injuries/fatalities and $11.29 \%$ resulted in damages, respectively. After that, $27.81 \%$ of accidents that happened at night resulted in injuries/fatalities (24.1\%) and damages (3.71\%), respectively, followed by $1.05 \%$ and $0.08 \%$ of sunrise/sunset accidents for them, respectively. So, the lowest percentage of accidents was during sunrise/sunset time.

3.1.8. Effect of Type of Vehicle Accident. Figure 9(a) shows that the largest type of vehicle accidents involved in a road traffic accident (RTA) was car-motorcycle/bike accidents that $41.15 \%$ of accidents were males and $1.98 \%$ were females, followed by getting off the road accidents $(22.37 \%$ for males and $0.93 \%$ for females) and car-car accidents $(24.02 \%$ for males and $1.21 \%$ for females). The lowest percentage of vehicle accidents was related to car-heavy truck accidents by male drivers $(0.52 \%)$ and female drivers $(0 \%)$. Results in Figure 9(b) shows that the highest percentage of injury/fatal vehicle accidents (42.52\%) was car-motorcycle/bike accidents and the least in injuries/fatalities was car-heavy truck accidents $(0.20 \%)$. Car-car accidents were also the leading cause of damages (5.93\%), and the least damages were occurred in car-agricultural machinery accidents $(0.12 \%)$. 


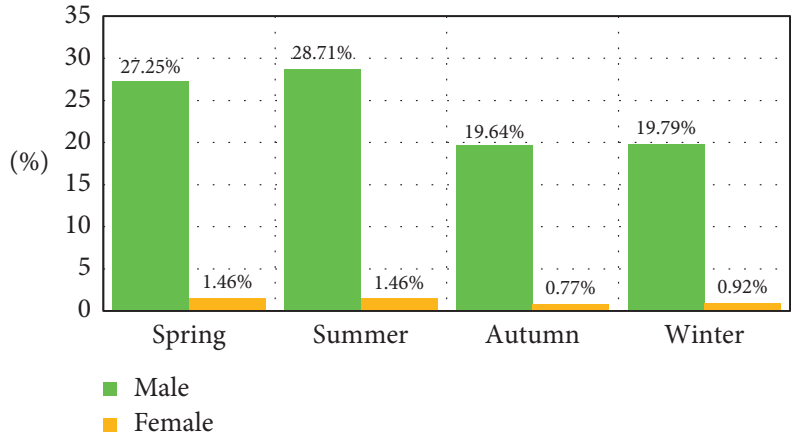

(a)

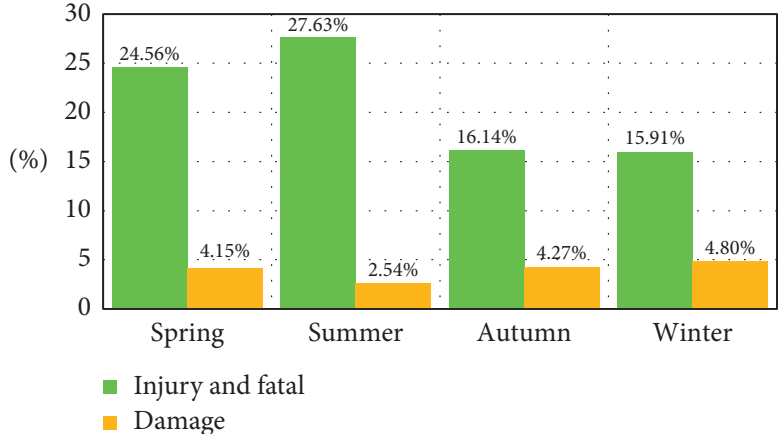

(b)

Figure 5: Accident statistics based on accident season and (a) driver gender; (b) accident severity.

$(\%)$

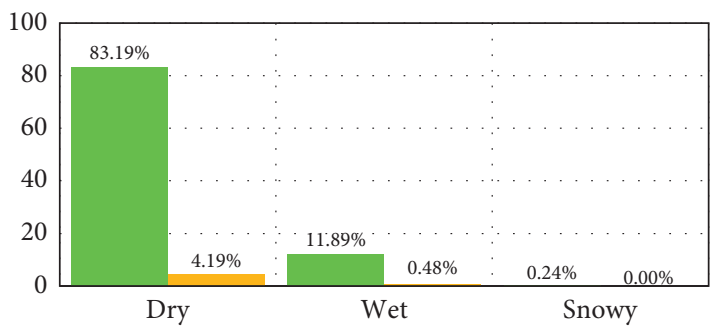

$$
\text { - Male }
$$

- Female

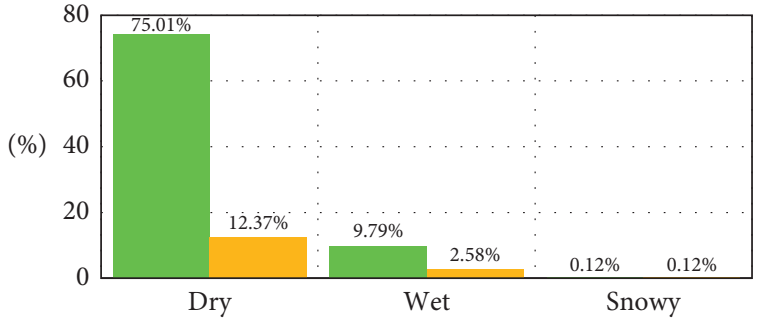

- Injury and fatal

- Damage

(a)

(b)

Figure 6: Accident statistics based on road surface condition and (a) driver gender; (b) accident severity.

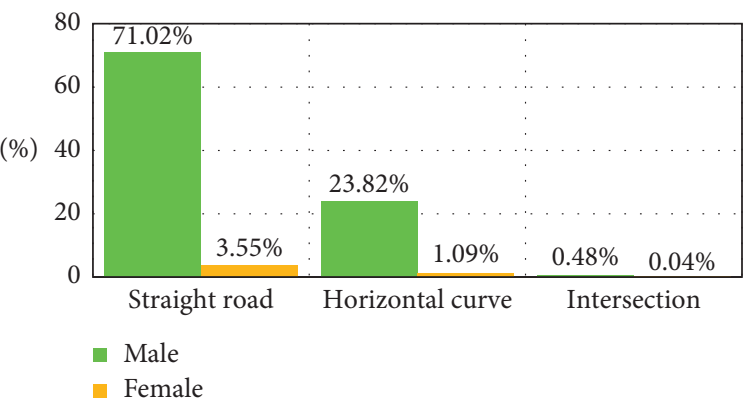

(a)

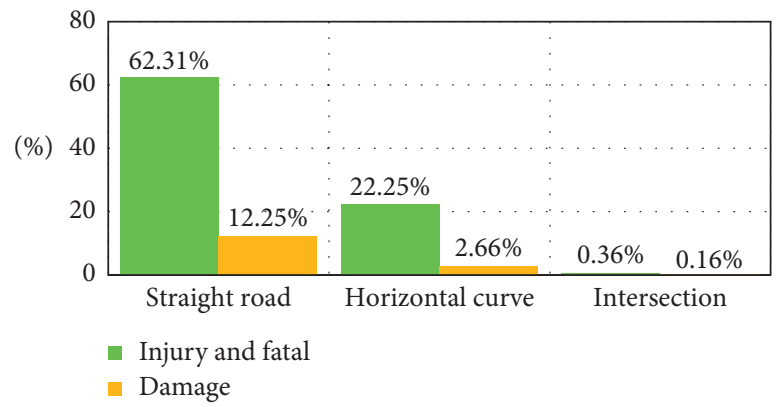

(b)

FIgURE 7: Accident statistics based on geometry of accident location and (a) driver gender; (b) accident severity.

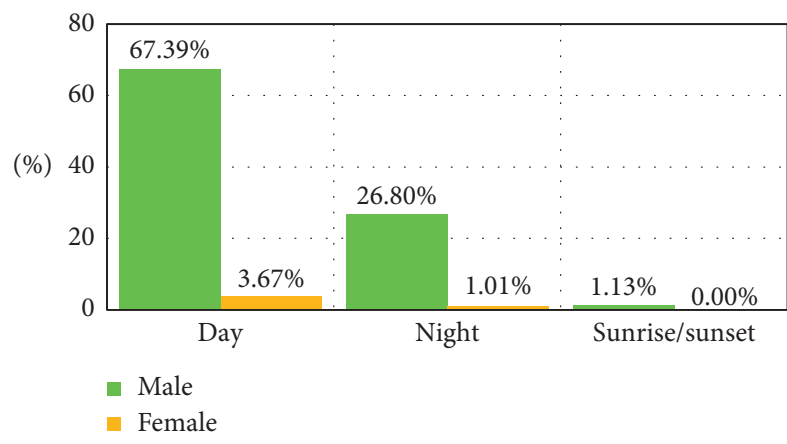

(a)

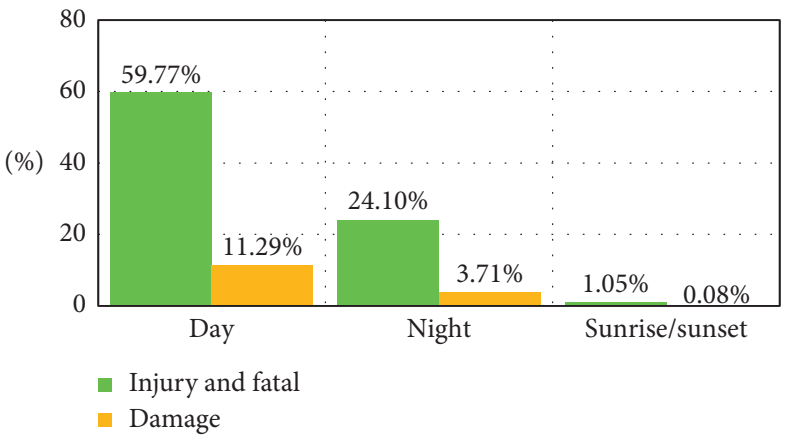

(b)

Figure 8: : Accident statistics based on daylight condition and (a) driver gender; (b) accident severity. 


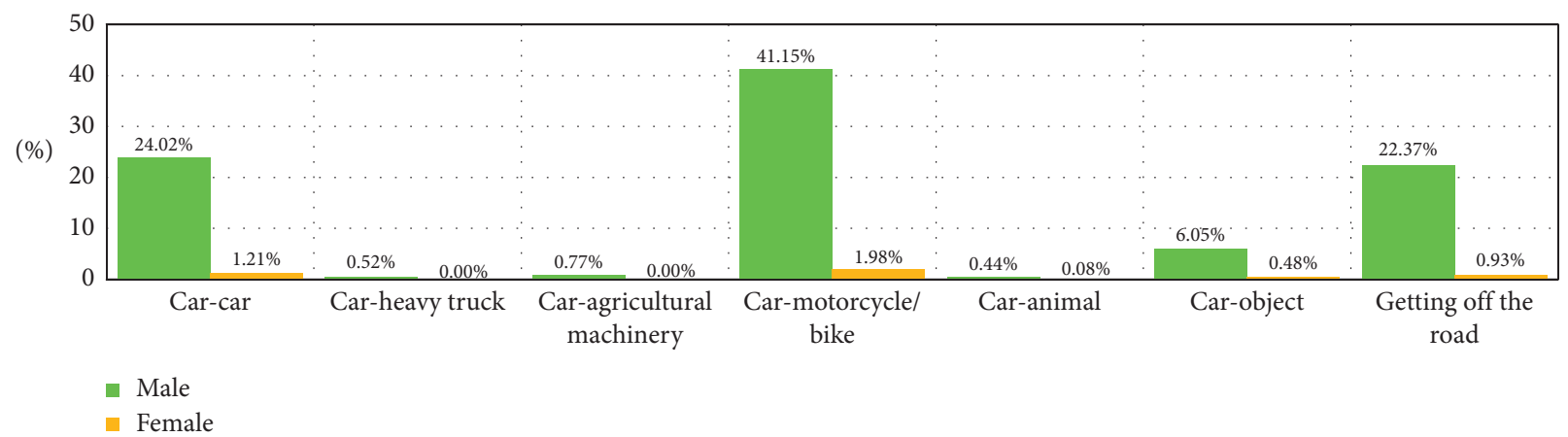

(a)

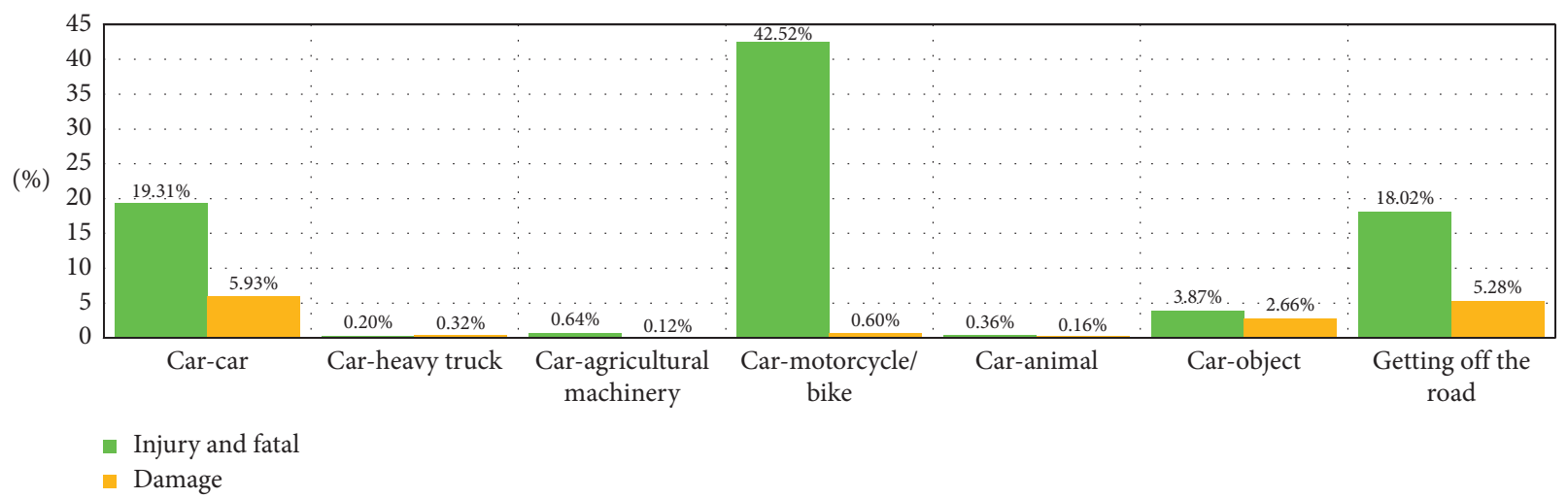

(b)

Figure 9: Accident statistics based on type of vehicle accident and (a) driver gender; (b) accident severity.

3.1.9. Effect of Driver Age and Gender. In this research, drivers were categorized into five age groups and both injury/fatal and damage accidents were higher among males than females, as shown in Figure 10(a). Percentages of accidents were prepared for the two genders for all age categories. Results indicated that greater male and female accident rates were in the age group of 30 to $45(35.91 \%$ and $2.34 \%$, respectively). The lowest male and female accident rates were $2.98 \%$ and $0.04 \%$, with the age group less than or equal to 18, as shown in Figure 10(a). Also, the age groups of 60 and over had the lowest percentage of accidents in females. According to Figure 10(b), the most injury/fatal and damage accidents were in drivers at the age of 30 to 45 (31.76\% and $6.49 \%$, respectively) and the lowest age at which injury/fatal and damage accidents occurred $(2.82 \%$ and $0.2 \%$, respectively) was in the age group less than or equal to 18.

3.1.10. Effect of Weather Condition. Male and female accident rates were compared in four different weather conditions: clear/sunny, cloudy, rainy, and snowy. Results obtained on weather conditions for both male and female accidents are illustrated in Figure 11(a). The higher male and female accident percentages were observed in clear/sunny weather $(76.78 \%$ for males; $3.67 \%$ for females), and snowy weather had the lowest percentage of accidents for both of them $(0.52 \%$ and $0 \%$, respectively). Statistics showed no female accidents on rural roads of Guilan in snowy weather.
Clear/sunny weather had the highest percentage of both injury/fatal and damage accidents $(68.8 \%$ and $11.65 \%$, respectively), and the lowest percentage of these accidents was due to the snowy weather ( $0.28 \%$ and $0.24 \%$, respectively), as shown in Figure 11(b).

3.2. Kolmogorov-Smirnov Test. For evaluating the normality of the data, first, the statistical distribution of the data should be ensured. So, the K-S test was applied to check the normality of the data distribution. Table 1 shows the results of this test.

As shown in Table 1, the significance level in the K-S test (represented by sig.) was less than 0.05 and considering $5 \%$ error, the null hypothesis $\left(H_{0}\right)$ was rejected, which is the natural distribution of the variables, and $H_{1}$ was accepted. So, the distribution was not normal and nonparametric tests were used.

3.3. Friedman Test. In the research, 11 independent variables were presented that the rank of each of these variables was examined by the FT. The FT can be applied to evaluate the rank equality of variable levels. Table 2 shows the statistical significance in which the statistical sample volume, chisquare statistic, degrees of freedom, and the level of significance ( $\alpha$ that represented by sig.) are represented.

As shown in Table 2, a lower level of significance of $\alpha$ than $5 \%$ indicated that $\mathrm{H}_{0}$ was rejected, which shows that claiming the rank equal was not accepted. As a result, ratings 


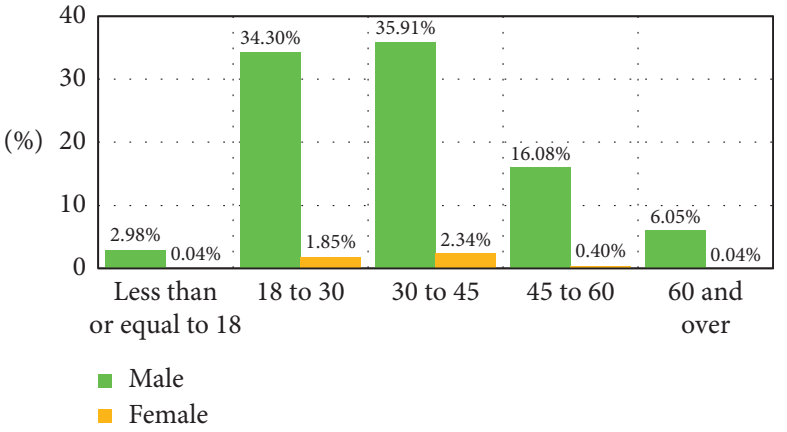

(a)

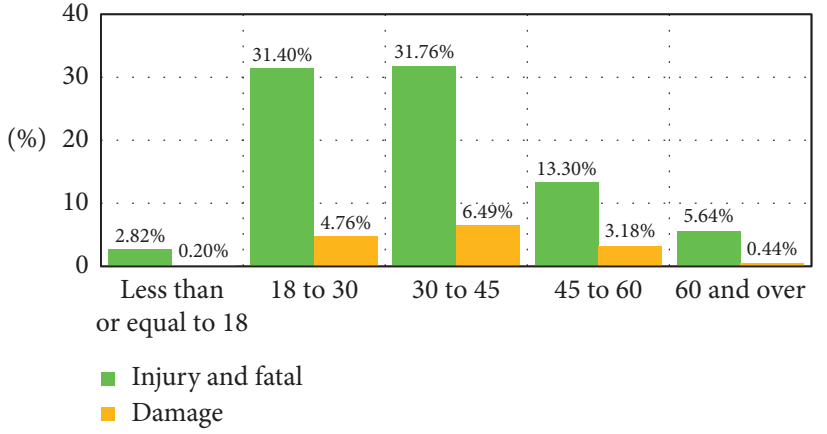

(b)

Figure 10: Accident statistics based on driver age and (a) driver gender; (b) accident severity.

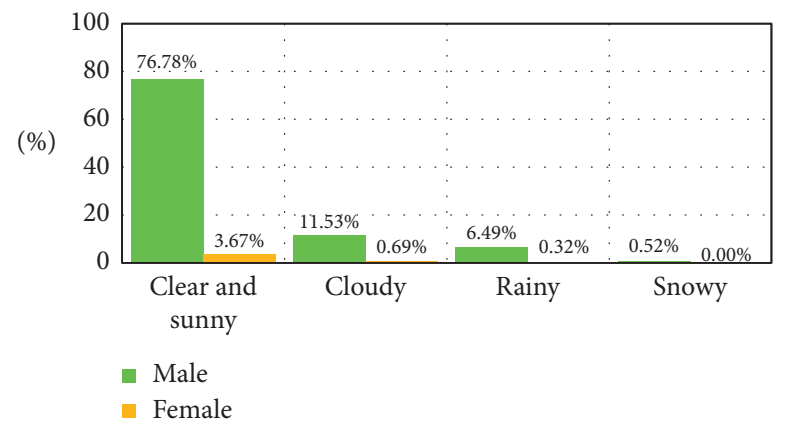

(a)

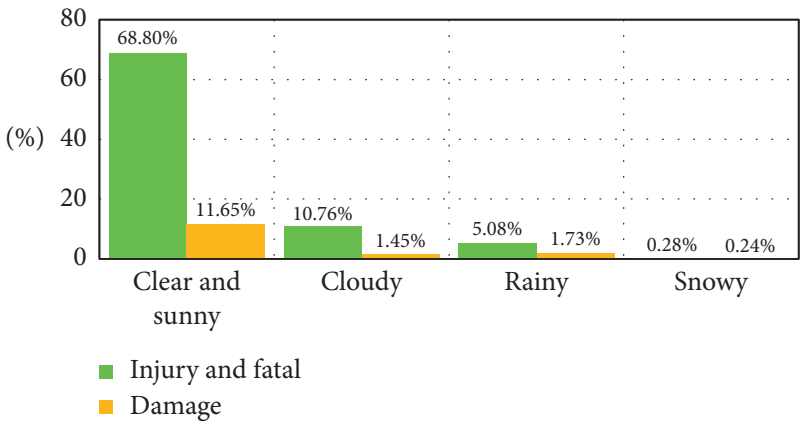

(b)

Figure 11: Accident statistics based on weather condition and (a) driver gender; (b) accident severity.

were not uniform. In Table 3, the ranking status of the independent variables is presented, indicating the mean rating of each variable. The smaller the mean rating, the greater the importance of the variable.

According to Table 3, the variables of weather condition, road surface condition, and type of vehicle accident had the highest rank, respectively, with the test score of 3.22, 3.48, and 3.99, respectively. On the other hand, the variables of geometry of accident location, accident day, and driver gender were the least important factors in the occurrence of accidents, showing that weather condition as an environmental factor had the greatest impact on the occurrence of vehicle accidents in the rural roads and then road surface condition as a road factor and the second most effective factor in increasing the occurrence of accidents. Type of vehicle accident also was identified as the third most influential factor in these accidents.

3.4. Factor Analysis. Table 4 indicates the result of the FA, including the KMO index and the Bartlett test.

According to Table 4, the KMO amount was 0.507, indicating that it was appropriate to use FA. Bartlett's test results showed that approximate chi-square was much larger than five. Also, the level of significance of the test statistic was less than 0.05 , meaning that the alternative hypothesis was confirmed and there was a significant correlation between the variables. Therefore, all the factors of the research were effective in investigating the severity of accidents, and in other words, the relationship between all components was confirmed.

Table 5 shows the eigenvalues and variance corresponding to each component. Eigenvalues specify the components that remain in the analysis. Whatever the eigenvalue of a component is greater, that component indicates more variance. In fact, components with an eigenvalue of less than 1 are excluded from the analysis. In Table 5, three parameters of initial eigenvalues, eigenvalues of nonrotating, and postrotating extraction components are given.

In Table 5, components 1 to 5 had eigenvalues greater than one. So, they remained in the analysis. Due to the eigenvalues of nonrotating extraction components, five components could explain the variances and variability of variables and contained approximately $58 \%$ of the variance. In Table 6 , the component matrix is presented before rotation, which shows the component loads of each variable in the remaining components.

Due to the difficulty of interpreting nonrotating component loads, the components were rotated to make interpretation easier. In other words, in the component matrix before rotation, the first component expressed a higher percentage of variation, whereas in the components rotation method, each of the remaining components represented an almost identical proportion of the total change explained by the three parameters mentioned. Table 7 shows the rotation matrix of the remaining components, which the extraction 
TABLE 1: The K-S test result.

\begin{tabular}{|c|c|c|c|c|c|c|}
\hline \multirow{2}{*}{ Number } & \multirow{2}{*}{ Variables } & \multicolumn{3}{|c|}{ Most extreme differences } & \multirow{2}{*}{ Test statistic } & \multirow{2}{*}{ Asymp. sig. (2-tailed) } \\
\hline & & Absolute & Positive & Negative & & \\
\hline 1 & Accident time & 0.242 & 0.194 & -0.242 & 0.242 & 0.0 \\
\hline 2 & Accident day & 0.222 & 0.204 & -0.222 & 0.222 & 0.0 \\
\hline 3 & Accident season & 0.207 & 0.207 & -0.142 & 0.207 & 0.0 \\
\hline 4 & Road surface condition & 0.520 & 0.520 & -0.353 & 0.520 & 0.0 \\
\hline 5 & Geometry of accident location & 0.467 & 0.467 & -0.286 & 0.467 & 0.0 \\
\hline 6 & Daylight condition & 0.444 & 0.444 & -0.267 & 0.444 & 0.0 \\
\hline 7 & Type of vehicle accident & 0.221 & 0.207 & -0.221 & 0.221 & 0.0 \\
\hline 8 & Driver age & 0.216 & 0.216 & -0.166 & 0.216 & 0.0 \\
\hline 9 & Driver gender & 0.541 & 0.541 & -0.413 & 0.541 & 0.0 \\
\hline 10 & Weather condition & 0.472 & 0.472 & -0.318 & 0.472 & 0.0 \\
\hline 11 & Reason of accident & 0.295 & 0.295 & -0.219 & 0.295 & 0.0 \\
\hline
\end{tabular}

TABle 2: The FT results.

\begin{tabular}{lccc}
\hline Number of data & Chi-square & Degrees of freedom & Asymp. sig. \\
\hline 2481 & 13965.319 & 10 & 0.0 \\
\hline
\end{tabular}

TABle 3: Mean rank in the FT.

\begin{tabular}{lcc}
\hline Variables & Mean & Rank \\
\hline Weather condition & 3.22 & 1 \\
Road surface condition & 3.48 & 2 \\
Type of vehicle accident & 3.99 & 3 \\
Accident time & 4.57 & 4 \\
Daylight condition & 5.13 & 5 \\
Accident season & 5.53 & 6 \\
Reason of accident & 6.24 & 7 \\
Driver age & 6.83 & 8 \\
Geometry of accident location & 7.18 & 9 \\
Accident day & 7.51 & 10 \\
Driver gender & 7.97 & 11 \\
\hline
\end{tabular}

TABLE 4: KMO and Bartlett's test.

\begin{tabular}{lcc}
\hline KMO measure of sampling adequacy. & 0.507 \\
& Approx. chi-square & 2156.045 \\
Bartlett's test of sphericity & Df & 55 \\
& Sig. & 0.0 \\
\hline
\end{tabular}

method in both matrices was principal component analysis and the rotation technique was Equamax with Kaiser Normalization. The values in Tables 6 and 7 indicate the degree of correlation of the relevant variable with the relevant components.

In the FA, the influence of variables on the severity of accidents was expressed using the coefficients listed in the rotated component matrix table. The greater the absolute magnitude of the coefficients of each variable, the more effective the desired component in total changes of each variable. The FA was performed on 11 independent variables affecting vehicle accidents on rural roads of Guilan, which identified five components as the main components. The analysis showed that the variables of weather condition and road surface condition were under the first component that the significant coefficients between the first component and each variable were 0.899 and 0.892 and positive, respectively. Therefore, it can be said that weather condition and road surface condition were the first factors affecting the occurrence of vehicle accidents on these rural roads, which had a large impact (depending on the size of the coefficient) on the occurrence of accidents. Also, daylight condition and accident time were under the second most influential components in accidents with positive coefficients ( 0.808 and 0.793 , respectively) that positively affected the occurrence of accidents. Similarly, type of vehicle accident and reason of accident variables were under the third component (with coefficients of 0.796 and 0.778 , respectively), geometry of accident location and accident season (with coefficients of -0.783 and 0.632 , respectively, in which negative coefficient indicates that the variable had a significant effect on reducing accidents) were under the fourth component, and finally, driver age and driver gender (with coefficients of -0.679 and 0.595 , respectively) were considered as the fifth most effective factor in vehicle accidents on rural roads of Guilan.

3.5. Comparisons. The current study investigated the risk factors of accident severity in vehicle accidents on rural roads of Guilan by applying several analysis methods to determine more precisely the variables affecting the severity of vehicle accidents. Results provided insight regarding the relationship between the various risk factors and accident severity for enhancing traffic safety on these roads. Each of these methods, considering their own specific algorithms, investigated the effective variables. So, to summarize the results using different methods, the results should be compared with each other. In the FT, the variables of weather condition, road surface condition, and type of vehicle accident were among the first to third rankings that caused accidents. While in the FA, the variables of weather condition and road surface condition were identified as the first effective factor, and daylight condition and accident time were recognized as the second effective factor in vehicle accidents. This illustrates that the joint result of the FT and FA, weather condition as an environmental factor, was recognized as the most important factors effective in vehicle accidents on rural roads of Guilan. 
TABLE 5: Total variance explained.

\begin{tabular}{lcccccccc}
\hline \multirow{2}{*}{ Component } & \multicolumn{3}{c}{ Initial eigenvalues } & \multicolumn{3}{c}{ Extraction sums of squared loadings } & \multicolumn{2}{c}{ Rotation sums of squared loadings } \\
& Total & \% of variance & Cumulative \% & Total & \% of variance & Cumulative \% & Total & \% of variance \\
Cumulative \%
\end{tabular}

TABle 6: Component matrix before rotation.

\begin{tabular}{lccccc}
\hline \multirow{2}{*}{ Variables } & \multicolumn{5}{c}{ Component } \\
& 1 & 2 & 3 & 4 & 5 \\
\hline Accident time & 0.185 & 0.763 & 0.080 & 0.071 & -0.110 \\
Accident day & 0.041 & -0.059 & -0.231 & 0.264 & 0.275 \\
Accident season & 0.250 & 0.077 & -0.070 & -0.315 & 0.543 \\
Road surface condition & 0.871 & -0.146 & -0.127 & 0.051 & -0.029 \\
Geometry of accident & 0.022 & -0.128 & -0.062 & 0.661 & -0.439 \\
location & & & & & \\
Daylight condition & 0.250 & 0.742 & 0.222 & 0.071 & 0.014 \\
Type of vehicle & 0.109 & -0.129 & 0.751 & 0.271 & 0.062 \\
accident & & & & & \\
Driver age & 0.158 & -0.179 & 0.075 & -0.499 & -0.448 \\
Driver gender & -0.055 & -0.125 & -0.044 & 0.340 & 0.496 \\
Weather condition & 0.875 & -0.187 & -0.087 & 0.061 & -0.012 \\
Reason of accident & 0.065 & -0.227 & 0.754 & -0.108 & 0.111 \\
\hline
\end{tabular}

TABle 7: Rotated component matrix.

\begin{tabular}{lccccc}
\hline \multirow{2}{*}{ Variables } & \multicolumn{5}{c}{ Component } \\
& 1 & 2 & 3 & 4 & 5 \\
\hline Accident time & 0.008 & 0.793 & -0.081 & -0.016 & -0.060 \\
Accident day & 0.100 & -0.069 & -0.136 & -0.004 & 0.413 \\
Accident season & 0.187 & 0.043 & -0.023 & 0.632 & 0.173 \\
Road surface condition & 0.892 & 0.047 & -0.009 & 0.028 & -0.019 \\
Geometry of accident & 0.132 & -0.012 & -0.013 & -0.783 & 0.141 \\
location & & & & & \\
Daylight condition & 0.051 & 0.808 & 0.082 & 0.074 & -0.001 \\
Type of vehicle & 0.045 & 0.076 & 0.796 & -0.150 & 0.085 \\
accident & 0.151 & -0.162 & 0.005 & 0.048 & -0.679 \\
Driver age & -0.006 & -0.120 & 0.089 & 0.075 & 0.595 \\
$\begin{array}{l}\text { Driver gender } \\
\text { Weather condition }\end{array}$ & 0.899 & 0.018 & 0.041 & 0.029 & -0.008 \\
Reason of accident & -0.012 & -0.080 & 0.778 & 0.137 & -0.133 \\
\hline
\end{tabular}

During the study period, 2481 vehicle accidents occurred on the rural roads of Guilan, which resulted in $84.92 \%$ injuries/fatalities and $15.08 \%$ damages, respectively. 20182019 had the lowest number of accidents with 428 cases and 2015-2016 had the highest number with 562 cases. In terms of gender, $95.32 \%$ of drivers in vehicle accidents were male and only $4.68 \%$ were females. $12 \mathrm{pm}$ to $6 \mathrm{pm}$ was identified as the most dangerous accident hours and 12 am to 6 am was recognized the safest. However, in general, considering the accidents at other times, most of the accidents happened in the daytime. The examination of the number of accidents on a weekly basis showed that the highest number was in the middle of the week. Summer and spring seasons, respectively, were the most dangerous seasons and autumn and then winter were the safest seasons. Most of the accidents in the province on rural roads occurred in dry surface condition, straight road, and in clear and sunny weather. Examination of the type of vehicle involved in accidents showed that car-motorcycle/bike accidents had the highest share. Also, based on the results of driver age, both male and female drivers aged 30 to 45 and then with a slight difference, drivers aged 18 to 30 had the highest accident rates. Finally, the results of reason of accident showed that invasion to left and right and then inability to control were identified as the most important reason of accidents.

Given that most accidents occurred from $12 \mathrm{pm}$ to $6 \mathrm{pm}$ and in the middle of the week, it can be said that these accidents were mostly due to return trips from work. Then, most of the accidents occurred on the weekends due to the increased travel to the province from elsewhere, and on the other hand, due to the high rate of motorcycle and bike accidents, high traffic of motorcycles and bicycles on these roads was one another major cause of accidents in these areas in which appropriate safety measures should be adopted. Given the high rate of accidents in the summer and after the spring and due to the favorable climate of the province, high rates of excursions were another reason for accidents along these roads. The least accidents occurred in the autumn and winter, respectively, which could be due to adverse climatic conditions for travel, particularly reduced the use of motorcycles and bicycles and agricultural activities in the colder months of the year.

The reasons for using motorcycles/bikes can be locals' livelihoods, cheapness compared with cars, easy learning, and accessibility for people of all ages, youth unemployment, and the proximity of the villages to each other, which make the use of motorcycles/bikes in the province more prosperous. This can increase the likelihood of car-motorcycle/ bike accidents occurring.

The results of this study in comparison with the previous studies showed that the greatest multitude of accidents 
happened during the daytime, similar to some studies $[80,81,83,85,87,100]$. In opposition, Soltani et al., represented the highest number of accidents at night [101]. Results also showed that most accidents happened at 12 to 18 , which confirms others $[81,83,85]$. Taking into account the days of the week, the results showed that most of the accidents occurred in the middle of the week that is in accordance with some previous studies [80, 85, 87], considering that the mid-week days also include working days. The maximum number of accidents was in summer and the minimum number of them occurred in autumn season probably because of more using of the vehicle in summer on rural roads of Guilan that is consistent with other studies that have shown that most accidents occurred in summer $[77,85]$ and is in contrast with some other studies which indicated more accident occurred in winter because of snowy and slippery roads [102]. This may be because that region had more snowfall than the study area of this research. Considering road surface conditions, the highest number of accidents occurred on dry surface and then most accidents were recorded on wet surface that confirms the study of Mayora and Piña [103], which showed that most accidents occurred on dry road conditions. The results also indicated that straight road had the highest accident rates among the other types which other studies confirm [83, 87]. This research indicated that RTAs involving a motorcycle/ bike were most common, which is consistent with others $[77,82,83,86]$. Motorcyclists/cyclists have been classified as vulnerable road users since they are not protected properly and share the road with high-speed vehicles and therefore are at greater risk [86]. The result that male motorcyclist/ cyclist was more frequent than female ones is consistent with some research studies on road accidents $[84,104]$ and with some other research studies indicating that male riders were at the highest risk of the accidents [104, 105]. The highest male-to-female ratio was due to the fact that in Iran, females usually do not ride a motorcycle/bike alone legally. Generally, the study revealed that the proportion of male drivers was much greater than the proportion of female drivers in rural road accidents, which is in line with others $[77,80-86,106]$. It can be attributed to the fact that they are more prone to high-risk behaviors or unsafe road practices. The age group most affected by rural road accidents in this study was 30-45 [80], followed by $18-30$, which affirms the findings from other surveys [77, 81, 82, 84-86, 106, 107]. With respect to weather condition, the highest accident rate occurred in the condition of clear and sunny weather that is in line with the results of other research studies [80, 85, 87]. Reason of accidents showed that invasion to left and right and then inability to control led to the highest number of accidents which is similar to Richter et al. results [108].

\section{Conclusion}

In this research, after analyzing the accident data to make a better decision, by statistical analysis of accidents, the causes of the risk of accident of Guilan have been concluded. Also, for the more practical use of this study, some suggestions have been made regarding the results. The most important results of the frequency analysis are as follows:

(i) The result of the K-S test indicated that the test was significant and therefore, the independent variables did not have a normal distribution. As a result, nonparametric tests were applied.

(ii) In the FT, the most important factors affecting vehicle accidents were weather condition, road surface condition, and type of vehicle accident, and this indicates that the most influential factor affecting these accidents on rural roads of Guilan was weather condition as an environmental factor and the second most important factor was road surface condition as an environmental factor (like weather condition) affecting the occurrence of accidents. Therefore, according to the FT results, environmental factor had the greatest impact on the occurrence of accidents.

(iii) Based on the FA, five factors were identified as the main factors affecting Guilan rural accidents. In other words, 11 effective variables in accidents have been reduced to five factors separately. The FA showed that the variables of weather condition and road surface condition were under the first factor affecting the occurrence of accidents. Therefore, the environmental factor (as the first factor) was the most important factor in the occurrence of accidents. The variables of daylight condition and accident time were under the second factor; type of vehicle accident and reason of accident were under the third factor; geometry of accident location and accident season were under the fourth factor; and driver age, driver gender, and accident day were under the fifth effective factor in occurrence of vehicle accidents in Guilan.

(iv) For the future work and analysis, we will deal with some state-of-the-art machine learning [14-19, 27, 37, 38, 109-112] and optimization algorithms $[8,11,13,113-115]$ to be incorporated with the proposed approach to attain more accuracy. Also, in future works, we will investigate factor analysis in more varieties of topics such as analysis of optimal water resources [116], analysis of multicriteria design of shale-gas-water supply chains [117], life cycle assessment of greenhouse gas emissions [118], coupling system dynamics analysis [119], assessing the global potential of aquifer thermal energy storage [120], analysis of process development [121], analysis of shape measurement [122], analysis of energy efficiency modeling [123], analysis of innovative oxidation processes [124-128], and pareto-based multiobjective optimization [129, 130].

\section{Safety Approach}

In order to decrease the number of accidents on rural roads of Guilan, it is necessary to consider all the factors together 
that are effective in the occurrence of accidents and provide appropriate solutions according to their importance. According to the analysis results, executable solutions that can be used to decrease rural road accident risks are as follows:

(i) Motorcyclists and cyclists were more likely to be involved in accidents due to the insufficient visibility of drivers. Therefore, they need to be careful about how the vehicle is moving (invasion to left and right, right of way violation, and inability to control), especially in clear and sunny weather. Wearing bright clothes and using lamps are recommended for motorcyclists and cyclists at night.

(ii) In addition to advertising on the radio, television, and urban advertising, police, municipal, forensic, and health organizations are recommended to gift luminous stickers for motorcyclists and cyclists for free.

(iii) Increasing the resolution and the number of signs and using reflective signs on low-speed vehicles on rural roads are recommended.

(iv) Given the high accident rates on straight roads, more police presence and control on these roads, especially from $12 \mathrm{pm}$ to $6 \mathrm{pm}$, are one of the best ways to reduce vehicle accidents. Also, considering most accidents occurring during the day and between $12 \mathrm{pm}$ to $6 \mathrm{pm}$, police control is better than night time. On the other hand, because the accident rate is also high from $6 \mathrm{pm}$ to 12 am (nights), it is recommended to use proper lighting on rural roads.

(v) Encouraging motorcyclists and cyclists to use helmets as well as enforcing stricter laws dealing with offenders and enacting laws that do not fully cover accident insurance for people without helmets may be appropriate measures to increase their willingness to use them.

(vi) Separating the path of motorcyclists and cyclists in hazardous areas by creating barriers between them and the road is an effective way to increase their safety.

(vii) Warning the drivers on straight road segments since geometry of accident location had effects on accidents. Warning signs or other pavement-based warning techniques, such as pavement marker and rumble strip, can help decrease the risk.

\section{Data Availability}

The data used to support the findings of this study are currently under embargo while the research findings are commercialized. Requests for data, 3 months after publication of this article, will be considered by the corresponding author.

\section{Conflicts of Interest}

The authors declare that they have no conflicts of interest.

\section{References}

[1] S. Hao and L. Yang, "Traffic network modeling and extended max-pressure traffic control strategy based on granular computing theory," Mathematical Problems in Engineering, vol. 2019, Article ID 2752763, 11 pages, 2019.

[2] A. Abdi, "Analysing the influence of encroachment angle and median parameters on safety of rural highways using vehicle dynamics performance," in Proceedings of the IOP Conference Series: Materials Science and Engineering, IOP Publishing, Bangkok, Thailand, May 2019.

[3] I. Bargegol, "Delay modeling of un-signalized roundabouts using neural network and regression," Computational Research Progress in Applied Science \& Engineering, vol. 2, pp. 28-34, 2016.

[4] S. Li, "A short-term traffic flow reliability prediction method considering traffic safety," Mathematical Problems in Engineering, vol. 2020, Article ID 6682216, 9 pages, 2020.

[5] Y. Li, "MTGPLP approach for traffic signal intelligent control," Mathematical Problems in Engineering, vol. 2020, Article ID 8603598, 18 pages, 2020.

[6] World Health Organization, Global Status Report on Road Safety 2018, WHO, Geneva, Switzerland, 2018.

[7] S. Wang, "Macrolevel traffic crash analysis: a spatial econometric model approach," Mathematical Problems in Engineering, vol. 2019, Article ID 5306247, 10 pages, 2019.

[8] X. Zhang, "Robust feature learning for adversarial defense via hierarchical feature alignment," Information Sciences, vol. 560, pp. 256-270, 2020.

[9] X. Zhang, T. Wang, W. Luo, and P. Huang, "Multi-level fusion and attention-guided CNN for image dehazing," IEEE Transactions on Circuits and Systems for Video Technology, vol. 1, p. 1, 2020.

[10] X. Zhang, M. Fan, D. Wang, P. Zhou, and D. Tao, “Top-k feature selection framework using robust 0-1 integer programming," IEEE Transactions on Neural Networks and Learning Systems, vol. 38, pp. 1-15, 2020.

[11] X. Zhang, "Robust low-rank tensor recovery with rectification and alignment," IEEE Transactions on Pattern Analysis and Machine Intelligence, vol. 43, no. 1, pp. 238-255, 2019.

[12] X. Zhang, R. Jiang, T. Wang, and J. Wang, "Recursive neural network for video deblurring," IEEE Transactions on Circuits and Systems for Video Technology, vol. 1, p. 1, 2020.

[13] X. Zhang, T. Wang, J. Wang, G. Tang, and L. Zhao, "Pyramid channel-based feature attention network for image dehazing," Computer Vision and Image Understanding, vol. 197198, Article ID 103003, 2020.

[14] H. Yu, "Dynamic Gaussian bare-bones fruit fly optimizers with abandonment mechanism: method and analysis," Engineering with Computers, vol. 7, pp. 1-29, 2020.

[15] C. Yu, "SGOA: annealing-behaved grasshopper optimizer for global tasks," Engineering with Computers, vol. 1, pp. 1-28, 2021.

[16] W. Shan, "Double adaptive weights for stabilization of moth flame optimizer: balance analysis, engineering cases, and medical diagnosis," Knowledge-Based Systems, vol. 214, Article ID 106728, 2020.

[17] J. Tu, H. Chen, J. Liu et al., "Evolutionary biogeographybased whale optimization methods with communication structure: towards measuring the balance," Knowledge-Based Systems, vol. 212, Article ID 106642, 2021.

[18] Y. Zhang, “Towards augmented kernel extreme learning models for bankruptcy prediction: algorithmic behavior and 
comprehensive analysis," vol. 430, , pp. 185-212, Neurocomputing, 2020.

[19] Y. Zhang, "Boosted binary Harris hawks optimizer and feature selection," Engineering with Computers, vol. 23, pp. 1-30, 2020.

[20] H.-L. Chen, G. Wang, C. Ma, Z.-N. Cai, W.-B. Liu, and S.-J. Wang, "An efficient hybrid kernel extreme learning machine approach for early diagnosis of Parkinson's disease," Neurocomputing, vol. 184, pp. 131-144, 2016.

[21] L. Hu, G. Hong, J. Ma, X. Wang, and H. Chen, "An efficient machine learning approach for diagnosis of paraquat-poisoned patients," Computers in Biology and Medicine, vol. 59, pp. 116-124, 2015.

[22] L. Shen, H. Chen, Z. Yu et al., "Evolving support vector machines using fruit fly optimization for medical data classification," Knowledge-Based Systems, vol. 96, pp. 61-75, 2016.

[23] J. Xia, H. Chen, Q. Li et al., "Ultrasound-based differentiation of malignant and benign thyroid Nodules: an extreme learning machine approach," Computer Methods and Programs in Biomedicine, vol. 147, pp. 37-49, 2017.

[24] C. Li, L. Hou, B. Y. Sharma et al., "Developing a new intelligent system for the diagnosis of tuberculous pleural effusion," Computer Methods and Programs in Biomedicine, vol. 153, pp. 211-225, 2018.

[25] X. Zhao, X. Zhang, Z. Cai et al., "Chaos enhanced grey wolf optimization wrapped ELM for diagnosis of paraquat-poisoned patients," Computational Biology and Chemistry, vol. 78, pp. 481-490, 2019.

[26] M. Wang and H. Chen, "Chaotic multi-swarm whale optimizer boosted support vector machine for medical diagnosis," Applied Soft Computing Journal, vol. 88, 2020.

[27] X. Xu and H.-l. Chen, "Adaptive computational chemotaxis based on field in bacterial foraging optimization," Soft Computing, vol. 18, no. 4, pp. 797-807, 2014.

[28] R. U. Khan, X. Zhang, R. Kumar, A. Sharif, N. A. Golilarz, and M. Alazab, "An adaptive multi-layer botnet detection technique using machine learning classifiers," Applied Sciences, vol. 9, no. 11, p. 2375, 2019.

[29] A. Addeh, A. Khormali, and N. A. Golilarz, "Control chart pattern recognition using RBF neural network with new training algorithm and practical features," ISA Transactions, vol. 79, pp. 202-216, 2018.

[30] N. Amiri Golilarz, "Adaptive wavelet based MRI brain image de-noising," Frontiers in Neuroscience, vol. 14, p. 728, 2020.

[31] N. A. Golilarz, H. Gao, and H. Demirel, "Satellite image denoising with Harris hawks meta heuristic optimization algorithm and improved adaptive generalized Gaussian distribution threshold function," IEEE Access, vol. 7, pp. 57459-57468, 2019.

[32] N. A. Golilarz, A. Addeh, H. Gao et al., "A new automatic method for control chart patterns recognition based on ConvNet and Harris hawks meta heuristic optimization algorithm," IEEE Access, vol. 7, pp. 149398-149405, 2019.

[33] B. Bai, Z. Guo, C. Zhou, W. Zhang, and J. Zhang, "Application of adaptive reliability importance sampling-based extended domain PSO on single mode failure in reliability engineering," Information Sciences, vol. 546, pp. 42-59, 2021.

[34] H. Chen, A. A. Heidari, H. Chen, M. Wang, Z. Pan, and A. H. Gandomi, "Multi-population differential evolutionassisted Harris hawks optimization: framework and case studies," Future Generation Computer Systems, vol. 111, pp. 175-198, 2020.
[35] Y. Cao, Y. Li, G. Zhang, K. Jermsittiparsert, and M. Nasseri, "An efficient terminal voltage control for PEMFC based on an improved version of whale optimization algorithm," Energy Reports, vol. 6, pp. 530-542, 2020.

[36] J. Liu, C. Wu, G. Wu, and X. Wang, "A novel differential search algorithm and applications for structure design," Applied Mathematics and Computation, vol. 268, pp. 246269, 2015.

[37] X. Zhao, D. Li, B. Yang, C. Ma, Y. Zhu, and H. Chen, "Feature selection based on improved ant colony optimization for online detection of foreign fiber in cotton," Applied Soft Computing, vol. 24, pp. 585-596, 2014.

[38] D. Zhao, "Chaotic random spare ant colony optimization for multi-threshold image segmentation of 2D Kapur entropy," Knowledge-Based Systems, vol. 216, Article ID 106510, 2020.

[39] J. Hu, H. Chen, A. A. Heidari et al., "Orthogonal learning covariance matrix for defects of grey wolf optimizer: insights, balance, diversity, and feature selection," Knowledge-Based Systems, vol. 213, Article ID 106684, 2021.

[40] N. Gao, D. Luo, B. Cheng, and H. Hou, "Teaching-learningbased optimization of a composite metastructure in the $0-10 \mathrm{kHz}$ broadband sound absorption range," The Journal of the Acoustical Society of America, vol. 148, no. 2, pp. EL125-EL129, 2020.

[41] G. Sun, "An adaptive differential evolution with combined strategy for global numerical optimization," Soft Computing, vol. 24, no. 9, pp. 6277-6296, 2019.

[42] G. Sun, C. Li, and L. Deng, "An adaptive regeneration framework based on search space adjustment for differential evolution," Neural Computing and Applications, vol. 32, pp. 1-17, 2021.

[43] D. Yu, Y. Mao, B. Gu, S. Nojavan, K. Jermsittiparsert, and M. Nasseri, "A new LQG optimal control strategy applied on a hybrid wind turbine/solid oxide fuel cell/in the presence of the interval uncertainties," Sustainable Energy, Grids and Networks, vol. 21, Article ID 100296, 2020.

[44] B. Wang, "Parallel lstm-based regional integrated energy system multienergy source-load information interactive energy prediction," Complexity, vol. 2019, Article ID 7414318, 13 pages, 2019

[45] J. Yan, W. Pu, S. Zhou, H. Liu, and M. S. Greco, "Optimal resource allocation for asynchronous multiple targets tracking in heterogeneous radar networks," IEEE Transactions on Signal Processing, vol. 68, pp. 4055-4068, 2020.

[46] H. Yue, H. Wang, H. Chen, K. Cai, and Y. Jin, “Automatic detection of feather defects using lie group and fuzzy Fisher criterion for shuttlecock production," Mechanical Systems and Signal Processing, vol. 141, Article ID 106690, 2020.

[47] H. Kordestani, C. Zhang, and M. Shadabfar, "Beam damage detection under a moving load using random decrement technique and Savitzky-Golay Filter," Sensors, vol. 20, no. 1, p. $243,2020$.

[48] H. Kordestani and C. Zhang, "Direct use of the savitzkygolay filter to develop an output-only trend line-based damage detection method," Sensors, vol. 20, no. 7, p. 1983, 2020.

[49] A. A. Mousavi, C. Zhang, S. F. Masri, and G. Gholipour, "Structural damage localization and quantification based on a ceemdan hilbert transform neural network approach: a model steel truss bridge case study," Sensors, vol. 20, no. 5, p. 1271, 2020.

[50] Q. Zhu, "Research on road traffic situation awareness system based on image big data," IEEE Intelligent Systems, vol. 35, no. 1, pp. 18-26, 2019. 
[51] Q. Jiang, "Unified no-reference quality assessment of singly and multiply distorted stereoscopic images," IEEE Transactions on Image Processing, vol. 28, no. 4, pp. 1866-1881, 2018.

[52] M. Xu, C. Li, S. Zhang, and P. L. Callet, "State-of-the-Art in $360^{\circ}$ video/image processing: perception, assessment and compression," IEEE Journal of Selected Topics in Signal Processing, vol. 14, no. 1, pp. 5-26, 2020.

[53] M. Yang and A. Sowmya, "An underwater color image quality evaluation metric," IEEE Transactions on Image Processing, vol. 24, no. 12, pp. 6062-6071, 2015.

[54] B. Wang, B. Zhang, and X. Liu, "An image encryption approach on the basis of a time delay chaotic system," Optik, vol. 225, Article ID 165737, 2021.

[55] S. Hinojosa, D. Oliva, E. Cuevas, G. Pajares, D. Zaldivar, and M. Pérez-Cisneros, "Reducing overlapped pixels: a multiobjective color thresholding approach," Soft Computing, vol. 24, no. 9, pp. 6787-6807, 2020.

[56] X. Zhao, Y. Ye, J. Ma, P. Shi, and H. Chen, "Construction of electric vehicle driving cycle for studying electric vehicle energy consumption and equivalent emissions," Environmental Science and Pollution Research, vol. 27, no. 30, pp. 37395-37409, 2020.

[57] T. Qiu, X. Shi, J. Wang et al., "Deep learning: a rapid and efficient route to automatic metasurface design," Advanced Science, vol. 6, no. 12, Article ID 1900128, 2019.

[58] T. Li, M. Xu, C. Zhu, R. Yang, Z. Wang, and Z. Guan, “A deep learning approach for multi-frame in-loop filter of HEVC," IEEE Transactions on Image Processing, vol. 28, no. 11, pp. 5663-5678, 2019.

[59] H. Chen, A. Chen, L. Xu et al., "A deep learning CNN architecture applied in smart near-infrared analysis of water pollution for agricultural irrigation resources," Agricultural Water Management, vol. 240, Article ID 106303, 2020.

[60] J. Qian, S. Feng, Y. Li et al., "Single-shot absolute 3D shape measurement with deep-learning-based color fringe projection profilometry," Optics Letters, vol. 45, no. 7, pp. 1842-1845, 2020.

[61] J. Qian, "Deep-learning-enabled geometric constraints and phase unwrapping for single-shot absolute $3 \mathrm{~d}$ shape measurement," APL Photonics, vol. 5, no. 4, Article ID 046105, 2020.

[62] J. Wang, "An adaptive neural sliding mode control with ESO for uncertain nonlinear systems," International Journal of Control, Automation and Systems, vol. 2020, pp. 1-11, 2020.

[63] Z. Chen, J. Wang, K. Ma, X. Huang, and T. Wang, "Fuzzy adaptive two-bits-triggered control for nonlinear uncertain system with input saturation and output constraint," International Journal of Adaptive Control and Signal Processing, vol. 34, no. 4, pp. 543-559, 2020.

[64] J. Wang, Y. Huang, T. Wang, C. Zhang, and Y. h. Liu, "Fuzzy finite-time stable compensation control for a building structural vibration system with actuator failures," Applied Soft Computing, vol. 93, Article ID 106372, 2020.

[65] Y. Huang, J. Wang, F. Wang, and B. He, "Event-triggered adaptive finite-time tracking control for full state constraints nonlinear systems with parameter uncertainties and given transient performance," ISA Transactions, vol. 108, pp. 131143, 2021.

[66] C. Li, L. Sun, Z. Xu, X. Wu, T. Liang, and W. Shi, "Experimental investigation and error analysis of high precision FBG displacement sensor for structural health monitoring," International Journal of Structural Stability and Dynamics, vol. 20, no. 06, Article ID 2040011, 2020.
[67] L. Sun, C. Li, C. Zhang, T. Liang, and Z. Zhao, "The strain transfer mechanism of fiber bragg grating sensor for extra large strain monitoring," Sensors, vol. 19, no. 8, p. 1851, 2019.

[68] C. Zhang, "Fibre Bragg grating sensor-based damage response monitoring of an asymmetric reinforced concrete shear wall structure subjected to progressive seismic loads," Structural Control and Health Monitoring, vol. 26, no. 3, p. e2307, 2019.

[69] L. Sun, C. Li, C. Zhang, Z. Su, and C. Chen, "Early monitoring of rebar corrosion evolution based on FBG sensor," International Journal of Structural Stability and Dynamics, vol. 18, no. 08, Article ID 1840001, 2018.

[70] I. Bargegol, V. N. M. Gilani, and F. Jamshidpour, "Relationship between pedestrians' speed, density and flow rate of crossings through urban intersections (case study: rasht metropolis) (RESEARCH NOTE)," International Journal of Engineering-Transactions C: Aspects, vol. 30, no. 12, pp. 1814-1821, 2017.

[71] H. Behbahani, "Analysis of crossing speed of the pedestrians in marked and unmarked crosswalks in the signalized and un-signalized intersections (case study: rasht city)," in Proceedings of the IOP Conference Series: Materials Science and Engineering, vol. 245, IOP Publishing, Kunming, China, October 2017.

[72] H. Behbahani, "Investigation of un-signalized roundabouts delay with adaptive-network-based fuzzy inference system and fuzzy logic," Computational Research Progress in Applied Science \& Engineering, vol. 2, no. 04, pp. 1-7, 2016.

[73] S. M. Hosseinian, V. Najafi Moghaddam Gilani, P. Mehraban Joobani, and M. Arabani, "Investigation of moisture sensitivity and conductivity properties of inductive asphalt mixtures containing steel wool fiber," Advances in Civil Engineering, vol. 2020, no. 1, 9 pages, Article ID 8890814, 2020.

[74] A. Abdi, "Dynamic modelling of the effects of combined horizontal and vertical curves on side friction factor and lateral acceleration," in Proceedings of the IOP Conference Series: Materials Science and Engineering, IOP Publishing, Bangkok, Thailand, May 2019.

[75] V. Najafi Moghaddam Gilani, S. M. Hosseinian, H. Behbahani, and G. H. Hamedi, "Prediction and paretobased multi-objective optimization of moisture and fatigue damages of asphalt mixtures modified with nano hydrated lime," Construction and Building Materials, vol. 261, Article ID 120509, 2020.

[76] N. Kamboozia, M. Ameri, and S. M. Hosseinian, "Statistical analysis and accident prediction models leading to pedestrian injuries and deaths on rural roads in Iran," International Journal of Injury Control and Safety Promotion, vol. 27, no. 4, pp. 493-509, 2020.

[77] S. T. Heydari, A. Hoseinzadeh, F. Ghaffarpasand et al., "Epidemiological characteristics of fatal traffic accidents in Fars province, Iran: a community-based survey," Public Health, vol. 127, no. 8, pp. 704-709, 2013.

[78] L. Shen, "Identification of accident blackspots on rural roads using grid clustering and principal component clustering," Mathematical Problems in Engineering, vol. 2019, Article ID 2151284, 12 pages, 2019.

[79] T. Litman and M. Hughes-Cromwick, "Public transportation's impact on rural and small towns: a vital mobility link," 2017.

[80] N. Casado-Sanz, B. Guirao, and D. Gálvez-Pérez, "Population ageing and rural road accidents: analysis of accident severity in traffic crashes with older pedestrians on Spanish 
crosstown roads," Research in Transportation Business \& Management, vol. 30, Article ID 100377, 2019.

[81] A. Ghaffar, A. A. Hyder, and T. I. Masud, "The burden of road traffic injuries in developing countries: the 1st national injury survey of Pakistan," Public Health, vol. 118, no. 3, pp. 211-217, 2004.

[82] M. Labinjo, C. Juillard, O. C. Kobusingye, and A. A. Hyder, "The burden of road traffic injuries in Nigeria: results of a population-based survey," Injury Prevention, vol. 15, no. 3, pp. 157-162, 2009.

[83] S. Hu and Q. Xiang, "Characteristics analysis of traffic accidents on rural roads," CICTP 2012: Multimodal Transportation Systems-Convenient, Safe, Cost-Effective, Efficient, vol. 1, pp. 2506-2513, 2012.

[84] H. Zangooei Dovom, Y. Shafahi, and M. Zangooei Dovom, "Fatal accident distribution by age, gender and head injury, and death probability at accident scene in Mashhad, Iran, 2006-2009," International Journal of Injury Control and Safety Promotion, vol. 20, no. 2, pp. 121-133, 2013.

[85] G. López, J. Abellán, A. Montella, and J. de Oña, "Patterns of single-vehicle crashes on two-lane rural highways in granada province, Spain," Transportation Research Record: Journal of the Transportation Research Board, vol. 2432, no. 1, pp. 133-141, 2014.

[86] K. Zimmerman, D. Jinadasa, B. Maegga, and A. Guerrero, "Road traffic injury on rural roads in Tanzania: measuring the effectiveness of a road safety program," Traffic Injury Prevention, vol. 16, no. 5, pp. 456-460, 2015.

[87] S. Lee and B. Y. Jeong, "Comparisons of traffic collisions between expressways and rural roads in truck drivers," Safety and Health at Work, vol. 7, no. 1, pp. 38-42, 2016.

[88] N. Kamboozia, M. Ameri, and S. M. Hosseinian, "Investigation of effective factors in the severity of rural road accidents in guilan to determine the most effective factors and provide safety solutions," Road, vol. 29, no. 106, pp. 115-128, 2021.

[89] Y. Xu, H. Chen, J. Luo, Q. Zhang, S. Jiao, and X. Zhang, "Enhanced Moth-flame optimizer with mutation strategy for global optimization," Information Sciences, vol. 492, pp. 181-203, 2019.

[90] M. Wang, H. Chen, B. Yang et al., “Toward an optimal kernel extreme learning machine using a chaotic moth-flame optimization strategy with applications in medical diagnoses," Neurocomputing, vol. 267, pp. 69-84, 2017.

[91] F. S. Nahm, "Nonparametric statistical tests for the continuous data: the basic concept and the practical use," Korean Journal of Anesthesiology, vol. 69, no. 1, p. 8, 2016.

[92] A. Rao, W. Han, and P. Senarathne, "A comparison of SLAM prediction densities using the Kolmogorov smirnov statistic," Unmanned Systems, vol. 04, no. 04, pp. 245-254, 2016.

[93] G. D. Ruxton, D. M. Wilkinson, and M. Neuhäuser, "Advice on testing the null hypothesis that a sample is drawn from a normal distribution," Animal Behaviour, vol. 107, pp. 249252, 2015.

[94] C. N. Kroll, K. E. Croteau, and R. M. Vogel, "Hypothesis tests for hydrologic alteration," Journal of Hydrology, vol. 530, pp. 117-126, 2015.

[95] I. Bargegol, V. Gilani, and S. Farghedayn, "Analysis of the effect of vehicles conflict on pedestrian's crossing speed in signalized and un-signalized intersection," Advances in Environmental Biology, vol. 8, no. 21, pp. 502-510, 2014.

[96] R. Eisinga, "Exact $p$-values for pairwise comparison of Friedman rank sums, with application to comparing classifiers," BMC Bioinformatics, vol. 18, no. 1, p. 68, 2017.
[97] N. Kamboozia, M. Ameri, and S. M. Hosseinian, "Statistical analysis and presentation of accident prediction model leading to injuries and deaths of pedestrians in rural roads of Gilan," Journal of Transportation Research, vol. 17, pp. 493-509, 2020.

[98] D. L. Bandalos and S. J. Finney, Factor Analysis: Exploratory and Confirmatory, in The Reviewer's Guide to Quantitative Methods in the Social Sciences, Routledge, England, UK, 2018.

[99] H. F. Kaiser, "An index of factorial simplicity," Psychometrika, vol. 39, no. 1, pp. 31-36, 1974.

[100] H. Sadeghi-Bazargani, B. Samadirad, N. Shahedifar, and M. Golestani, "Epidemiology of road traffic injury fatalities among car users; a study based on forensic medicine data in East Azerbaijan of Iran," Bulletin of Emergency and Trauma, vol. 6, no. 2, p. 146, 2018.

[101] G. Soltani, "Investigating prevalence of deaths from traffic accidents and factors associated with it in yazd in 2009," SSU_Journals, vol. 21, no. 6, pp. 831-839, 2014.

[102] A. Razzaghi, A. Bahrampour, M. R. Baneshi, and F. Zolala, "Assessment of trend and seasonality in road accident data: an Iranian case study," International Journal of Health Policy and Management, vol. 1, no. 1, p. 51, 2013.

[103] J. M. Pardillo Mayora and R. Jurado Piña, "An assessment of the skid resistance effect on traffic safety under wet-pavement conditions," Accident Analysis \& Prevention, vol. 41, no. 4, pp. 881-886, 2009.

[104] W. A. Harrison and R. Christie, "Exposure survey of motorcyclists in new south wales," Accident Analysis \& Prevention, vol. 37, no. 3, pp. 441-451, 2005.

[105] F. L. Mannering and L. L. Grodsky, "Statistical analysis of motorcyclists' perceived accident risk," Accident Analysis \& Prevention, vol. 27, no. 1, pp. 21-31, 1995.

[106] C. A. Butts, R. Gonzalez, L. Nguyen et al., "Twelve-year review of urban versus rural off-road vehicle injuries at a level 1 trauma center," Journal of Surgical Research, vol. 233, pp. 331-334, 2019.

[107] F. Mohtasham amiri, "Road traffic accidents, life-threatening phenomenon in guilan province: an epidemiologic study," Journal of Guilan University of Medical Sciences, vol. 23, no. 92, pp. 1-8, 2015.

[108] T. Richter, S. Ruhl, J. Ortlepp, and E. Bakaba, "Causes, consequences and countermeasures of overtaking accidents on two-lane rural roads," Transportation Research Procedia, vol. 25, pp. 1989-2001, 2017.

[109] J. Hu, "Orthogonal learning covariance matrix for defects of grey wolf optimizer: insights, balance, diversity, and feature selection," Knowledge-Based Systems, vol. 213, Article ID 106684, 2020.

[110] V. Najafi Moghaddam Gilani, "Investigation of the impact of deicer materials on thermodynamic parameters and its relationship with moisture susceptibility in modified asphalt mixtures by carbon nanotube," Arabian Journal for Science and Engineering, vol. 2020, 2020.

[111] G. H. Hamedi, "The effect of aggregate-forming minerals on thermodynamic parameters using surface free energy concept and its relationship with the moisture susceptibility of asphalt mixtures," Advances in Civil Engineering, vol. 2021, Article ID 8818681, 15 pages, 2021.

[112] V. Najafi Moghaddam Gilani, S. M. Hosseinian, and M. Nikookar, "Presentation of a new deicer with the least moisture and fatigue failures in asphalt mixtures," Arabian Journal for Science and Engineering, vol. 46, no. 2, 2021. 
[113] X. Zhang, “Top- $k$ feature selection framework using robust 0-1 integer programming," IEEE Transactions on Neural Networks and Learning Systems, vol. 1, pp. 1-15, 2020.

[114] X. Zhang, "Recursive neural network for video deblurring," IEEE Transactions on Circuits and Systems for Video Technology, vol. 99, no. 1, p. 1, 2020.

[115] X. Zhang, "Multi-level fusion and attention-guided CNN for image dehazing," IEEE Transactions on Circuits and Systems for Video Technology, vol. 99, p. 1, 2020.

[116] X. Cheng, L. He, H. Lu, Y. Chen, and L. Ren, "Optimal water resources management and system benefit for the Marcellus shale-gas reservoir in Pennsylvania and West Virginia," Journal of Hydrology, vol. 540, pp. 412-422, 2016.

[117] Y. Chen, L. He, J. Li, and S. Zhang, "Multi-criteria design of shale-gas-water supply chains and production systems towards optimal life cycle economics and greenhouse gas emissions under uncertainty," Computers \& Chemical Engineering, vol. 109, pp. 216-235, 2018.

[118] Y. Chen, L. He, Y. Guan, H. Lu, and J. Li, "Life cycle assessment of greenhouse gas emissions and water-energy optimization for shale gas supply chain planning based on multi-level approach: case study in Barnett, Marcellus, Fayetteville, and Haynesville shales," Energy Conversion and Management, vol. 134, pp. 382-398, 2017.

[119] Y. Chen, J. Li, H. Lu, and P. Yan, "Coupling system dynamics analysis and risk aversion programming for optimizing the mixed noise-driven shale gas-water supply chains," Journal of Cleaner Production, vol. 278, Article ID 123209, 2021.

[120] H. Lu, P. Tian, and L. He, "Evaluating the global potential of aquifer thermal energy storage and determining the potential worldwide hotspots driven by socio-economic, geo-hydrologic and climatic conditions," Renewable and Sustainable Energy Reviews, vol. 112, pp. 788-796, 2019.

[121] X. Han, D. Zhang, J. Yan, S. Zhao, and J. Liu, "Process development of flue gas desulphurization wastewater treatment in coal-fired power plants towards zero liquid discharge: energetic, economic and environmental analyses," Journal of Cleaner Production, vol. 261, Article ID 121144, 2020.

[122] C. Zuo, Q. Chen, G. Gu et al., "High-speed three-dimensional shape measurement for dynamic scenes using bifrequency tripolar pulse-width-modulation fringe projection," Optics and Lasers in Engineering, vol. 51, no. 8, pp. 953-960, 2013.

[123] C. Yang, F. Gao, and M. Dong, "Energy efficiency modeling of integrated energy system in coastal areas," Journal of Coastal Research, vol. 103, no. s1, pp. 995-1001, 2020.

[124] B. Wang, Z. Song, and L. Sun, "A review: comparison of multi-air-pollutant removal by advanced oxidation processes-industrial implementation for catalytic oxidation processes," Chemical Engineering Journal, vol. 409, no. 1, Article ID 128136, 2020.

[125] M. Yazdi, T. Saner, and M. Darvishmotevali, “Application of an artificial intelligence decision-making method for the selection of maintenance strategy," in Proceedings 10th International Conference on Theory and Application of Soft Computing, Computing with Words and Perceptions ICSCCW-2019, pp. 246-253, Springer, Cham, Switzerland, August 2020.

[126] M. Yazdi, "Ignorance-aware safety and reliability analysis: a heuristic approach," Qual Quality and Reliability Engineering International, vol. 36, no. 2, pp. 652-674, 2020.

[127] M. Yazdi, S. Daneshvar, and H. Setareh, "An extension to fuzzy developed failure mode and effects analysis (FDFMEA) application for aircraft landing system," Safety Science, vol. 98, pp. 113-123, 2017.

[128] M. Yazdi, "Acquiring and sharing tacit knowledge in failure diagnosis analysis using intuitionistic and pythagorean assessments," Journal of Failure Analysis and Prevention, vol. 19, no. 2, pp. 369-386, 2019.

[129] H. Behbahani, G. H. Hamedi, and V. Najafi Moghaddam Gilani, "Predictive model of modified asphalt mixtures with nano hydrated lime to increase resistance to moisture and fatigue damages by the use of deicing agents," Construction and Building Materials, vol. 265, Article ID 120353, 2020.

[130] A. Ghasemzadeh Mahani, "Experimental investigation and multi-objective optimization of fracture properties of asphalt mixtures containing nano-calcium carbonate," Construction and Building Materials, vol. 285, Article ID. 122876, 2021. 